OPEN ACCESS

Edited by:

Claire Anne Chougnet, Cincinnati Children's Hospital Medical Center Research Foundation, USA

Reviewed by: Keith R. Fowke, University of Manitoba, Canada Lishomwa Ndhlovu, University of Hawaii, USA

${ }^{*}$ Correspondence: Amy L. Slogrove slogrove@gmail.com

Specialty section: This article was submitted

to HIV and AIDS,

a section of the journal

Frontiers in Immunology

Received: 29 February 2016 Accepted: 18 April 2016

Published: 06 May 2016

Citation:

Slogrove AL, Goetghebuer T, Cotton MF, Singer $J$ and Bettinger JA (2016) Pattern of Infectious Morbidity

in HIV-Exposed Uninfected Infants and Children.

Front. Immunol. 7:164. doi: 10.3389/fimmu.2016.00164

\section{Pattern of Infectious Morbidity in HIV-Exposed Uninfected Infants and Children}

\author{
Amy L. Slogrove ${ }^{1,2 *}$, Tessa Goetghebuer ${ }^{3,4}$, Mark F. Cotton $^{1}$, Joel Singer ${ }^{2}$ and \\ Julie A. Bettinger ${ }^{5}$ \\ 'Division of Paediatric Infectious Diseases, Department of Paediatrics and Child Health, Faculty of Medicine and Health \\ Sciences, Stellenbosch University, Tygerberg, South Africa, ${ }^{2}$ School of Population and Public Health, University of British \\ Columbia, Vancouver, BC, Canada, ${ }^{3}$ Department of Paediatrics, St Pierre University Hospital, Brussels, Belgium, ${ }^{4}$ Université \\ Libre de Bruxelles, Brussels, Belgium, ${ }^{5}$ Division of Pediatric Infectious Diseases, Department of Pediatrics, Vaccine \\ Evaluation Center, BC Children's Hospital, University of British Columbia, Vancouver, BC, Canada
}

Background: Almost 30\% of children in Southern Africa are HIV exposed but uninfected (HEU) and experience exposures that could increase vulnerability to infectious diseases compared to HIV unexposed (HU) children. The mechanisms of HEU infant vulnerability remain ill-defined. This review seeks to appraise the existing clinical evidence of the pattern of HEU infant infectious morbidity to aid understanding of the potential mechanism of susceptibility.

Methods: A systematic search was conducted of scientific literature databases and conference proceedings up to December 2015 for studies comparing adequately defined HEU (in whom HIV-infection had been excluded through age-appropriate testing) and HU infants for all-cause mortality, all-cause hospitalization, or an infection-related morbidity. The systematic review was complemented by a narrative review of additional studies detailing the pattern of infectious morbidity experienced by HEU children without comparison to HU children or without conclusive exclusion of HIV-infection in HIV-exposed infants.

Results: Only 3 of 22 eligible identified studies were designed to primarily compare HEU and $\mathrm{HU}$ infants for infectious morbidity. Fourteen were conducted prior to 2009 in the context of limited antiretroviral interventions. Three patterns emerge: (1) causes of morbidity and mortality in HEU infants are consistent with the common causes of childhood morbidity and mortality (pneumonia, diarrheal disease, and bacterial sepsis) but occur with greater severity in HEU infants resulting in higher mortality, more frequent hospitalization, and more severe manifestations of disease; (2) the greatest relative difference between HEU and HU infants in morbidity and mortality occurs beyond the neonatal period, during mid-infancy, having waned by the second year of life; and (3) HEU infants are at greater risk than $\mathrm{HU}$ infants for invasive streptococcal infections specifically Group B Streptococcus and Streptococcus pneumonia. 
Conclusion: To definitively understand HEU infant infectious morbidity risk, substantially larger prospective studies with appropriate $\mathrm{HU}$ infant comparison groups are necessary. HEU children would benefit from collaboration among researchers to achieve the quality of evidence required to improve HEU infant outcomes globally. HEU infant health and well-being, beyond avoiding HIV-infection, deserves a more prominent position in the local and international HIV research agendas.

\section{Keywords: HIV exposed uninfected, HEU, infection, review, infant}

\section{INTRODUCTION}

Globally, approximately 1.4 million HIV-infected women become pregnant annually (1). Expanding vertical HIV transmission prevention (VTP) programs have markedly reduced HIV transmission, but for those HIV-exposed but uninfected (HEU) children, there are consequences of being born to an HIV-infected mother (1). HEU infants experience numerous exposures during fetal and early life that could increase their vulnerability to infectious diseases during infancy compared to HIV unexposed (HU) infants. Risk factors for HEU infant infectious morbidity and mortality can be divided into two groups: (1) Universal infant risk factors. These include prematurity or small for gestational age, absence of or suboptimal breastfeeding, maternal mortality, exposure to infectious agents particularly tuberculosis (TB), and poverty (2-11); (2) risk factors unique to HIV-exposed infants. These include exposure to the in utero environment altered by HIV, including exposure to viral proteins and glycoproteins, a pro-inflammatory state in the mother, maternal immune compromise, exposure to antiretroviral (ARV) and other drugs in utero and in breast milk (12-18). Understanding whether HIV-exposure plays a direct role in HEU infant risk for morbidity and mortality requires consideration of the universal infant risk factors as confounders to the relationship between HIV-exposure and infectious morbidity.

A number of perturbations of the HEU infant immune system, most likely as a result of HEU-unique exposures, have been observed (19). However, these immune system changes have not yet been studied in direct association with risk for infectious morbidity, probably the consequence of greatest importance for the majority of HEU infants and children living in regions experiencing high infectious disease-related child mortality (15, 20-26). Interrogation of the clinical pattern of infectious morbidity in HEU children could aid understanding of the potential mechanism of susceptibility and define a focus for further immunologic investigations within the vastness of the infant immune system. To this end, this review seeks to better understand the existing evidence of HEU infant vulnerability for infectious disease morbidity. Detailed reviews on HEU infant innate and humoral immunity are included in this special issue and will not be considered here.

\section{METHOD}

This paper comprises a systematic review of the literature for studies comparing infectious morbidity in HEU and HU infants and children, as well as a narrative review of two additional types of studies, the first detailing the pattern of infectious morbidity experienced by HEU infants and children without comparison to HU children, and the second, without conclusive exclusion of HIV infection in HIV-exposed infants. For the systematic review, the literature was searched for studies comparing adequately defined HEU (in whom HIV-infection had been excluded through age-appropriate serologic or virologic testing) and $\mathrm{HU}$ infants for all-cause mortality, all-cause hospitalization, or an infection-related morbidity. Databases searched up to December 2015 included Medline, Embase, Cochrane Central Register of Controlled Trials, Cochrane Database of Systematic Reviews, and the following conference proceedings: International AIDS Society Conference on HIV Pathogenesis, Treatment and Prevention; International AIDS Conference; Conference of Retroviruses and Opportunistic Infections. Reference lists of identified manuscripts were scrutinized for additional studies. The search term strategy is detailed in Table 1. The systematic search identified 498 studies. Following title review, the abstracts of 149 studies and full-text of 32 studies were reviewed. Twentytwo eligible studies are summarized, and their evidence is discussed.

\section{REVIEW}

Most of what is known about HEU infant infectious morbidity comes from observations made early in the epidemic describing the natural history of HIV infected children compared to HIV-uninfected children, both HIV exposed and unexposed, or from secondary analyses of VTP clinical trials often without an HU control group (16, 27-32). Twenty-two studies comparing adequately defined HEU to $\mathrm{HU}$ infants for all-cause mortality, all-cause hospitalization, or infectious morbidity were identified, 21 from sub-Saharan Africa and 1 from Denmark

\section{TABLE 1 | Search term strategy.}

Search terms

1. HIV infect* OR HIV OR HIV-1 OR HIV-2 OR HIV1 OR HIV2 OR human immune*

2. Infant OR child OR infan* OR childr* OR paediatric OR pediatric

3. Mortality OR morbidity OR infectio* OR diarrhoea OR diarrhea OR diarrh* OR pneumonia* OR pneumo* OR respiratory OR sepsis OR septic* OR bacteria* OR virus OR viral

4. HIV exposed uninfected OR HEU OR HIV-EU OR HIV unexposed OR HUU OR HU OR HIV-UE OR HIV-uninfected

5. 1 AND 2 AND 3 AND 4 
TABLE 2 | Studies comparing mortality and infectious morbidity in HIV-exposed uninfected and HIV-unexposed children in sub-Saharan Africa.

\begin{tabular}{|c|c|c|c|c|c|}
\hline Reference & $\begin{array}{l}\text { Country } \\
\text { (year) }\end{array}$ & $\begin{array}{l}\text { Study type; sample size } \\
\text { (HEU:HU) }\end{array}$ & Outcome & Follow-up & $\begin{array}{l}\text { Findings [HEU vs. HU; point estimate } \\
(95 \% \mathrm{Cl})]\end{array}$ \\
\hline
\end{tabular}

\section{All-cause mortality and hospitalization}

1. Spira et al. (28) Rwanda

$\begin{array}{ll}\text { 2. Taha et al. (29) } & \text { Malawi } \\ \text { 3. Brahmbhatt et al. (17) } & \text { Uganda }\end{array}$ (1994-1998)

4. Marinda et al. (33); Zimbabwe Koyanagi et al. (34) (1997-2000)

5. Shapiro et al. (35) Botswana (2000-2005)

6. Homsy et al. (36) Uganda (2007-2008)

7. Landes et al. (37) Malawi (2008-2009)

8. Moraleda et al. (38) Mozambique (2008-2009)

9. Slogrove et al. (39) South Africa (2009-2011)

10. Marquez et al. (40) Uganda (2010-2013)

11. Slogrove $e^{c}(41) \quad$ South Africa (2012-2014)

\section{Diarrhea-specific morbidity}

\section{Thea et al. (27) DRC (Zaire}

(1989-1992)

13. Rollins et al. (42) South Africa (2001-2005)

14. Pavlinac et al. (43) Kenya (2011-2013)

\section{Pneumonia-specific morbidity} $\begin{array}{ll}\text { 15. Izadnegahdar } & \text { South Africa } \\ \text { et al. (44) } & (1999-2001)\end{array}$

16. McNally et al. (45) South Africa (2001-2002)

17. Kelly et al. ${ }^{c}(46) \quad$ Botswana (2012-2013)

18. Le Roux et al. (47) South Africa (2012-2014)

\section{Other specific morbidity}

19. Cutland et al. (48) South Africa (2004-2007)

RCT (1255:5804)

Severe pneumonia RCT

(40:244)

Hospital cohort (41:75)

Prospective hospital cohort (64:153)

Birth cohort (130:567)

Breastfeeding intervention cohort (936:115)

Cross-sectional diarrhea surveillance (105:821)

All-cause hospitalization $\quad$ 0-24 months and mortality

Adverse event and

hospital admissions

All-cause hospitalization

Sick clinic visits and hospitalization

Infectious cause hospitalization

Morbidity and all-cause mortality

Infectious cause

hospitalization

Diarrhea incidence $\quad$ 0-12 months

Diarrheal morbidity and $\quad$ 0-18 months all-cause mortality

Enteric pathogen prevalence

Severe pneumonia treatment failure

Severe pneumonia treatment failure

Severe pneumonia treatment failure

Pneumonia incidence

Neonatal sepsis incidence

Otopathogen

Cross-sectional acute otitis surveillance (63:182)

Laboratory surveillance

(253 HEU cases:377 HU cases)
(2009-2010)

South Africa (2009-2013)

\section{prevalence}

IPD incidence ${ }^{\mathrm{a}}$ and mortality
0-48 months

0-20 months

0-12 months

0-12 months

6-24 months

0-6 months

(1)

$6-180^{\mathrm{b}}$ months

$3-59^{\mathrm{b}}$ months

$0-12^{\mathrm{b}}$ months

$1-23^{b}$ months

0-12 months

0-1 month

Severe pneumonia aHR $1.4(0.9,2.0)$; hospitalization aHR $1.3(0.9,1.4)$

No difference in numerous morbidities

Mortality 18 months alRR $1.16(p<0.05)$

Mortality: 2-6 months alRR 5.5 (3.9, 7.9); throughout 24 months alRR > $(1.2,7.9)$; hospitalization: neonatal alRR $1.5(1.2,2.0)$; post-neonatal alRR $1.2(0.9,1.6)$

Mortality aRR $4.2(p<0.01)$; Hospitalization aRR $2.17(p<0.001)$

No difference in incidence of hospitalization or grade $3 / 4$ adverse events

No difference in hospitalization

Sick clinic visit: uIRR $0.79(0.63,0.99)$; Hospitalization: UIRR $1.51(0.71,3.18)$

Sick clinic visit: uIRR $1.06(0.79,1.39)$; hospitalization: uIRR $2.74(0.75,8.78)$

No difference breastfed HEU and breastfed HU 6-11 months old

Sick clinic visit: uIRR $0.82(0.58,1.16)$; all hospitalization: aOR $1.45(0.4,4.5)$; very severe hospitalization: aOR $4.2(1.0,19.2)$

Persistent diarrhea incidence 4.9 vs. 2.7/100 py $(p=0.23)$

Diarrhea at 6 months aHR $1.45(0.75,2.79)$; mortality 12 months aHR $0.77(0.49,1.21)$;

Cryptosporidum spp. aPR 2.7 (1.3-5.6)

uOR $2.19(0.75-2.75)$

aOR $6.02(1.55,23.38)$

Treatment failure: aRR1.83 (1.27, 2.64); Mortality aRR 4.31 (1.44, 12.87)

All pneumonia: alRR $1.62(1.0,2.6)$; severe pneumonia: uIRR $4.04(1.5,10.8)$

Propensity score matched analysis: early onset (20.6 vs. 33.7/1000 live births); late onset (5.8 vs. 4.1 per 1000 live births)

$3-59^{\mathrm{b}}$ months No difference in type of otopathogens

0-12 ${ }^{\mathrm{b}}$ months $\quad$ IPD aRR 0-6 months $3.6(2.8,4.6)$; mortality due to IPD aOR $1.76(1.09,2.85)$

${ }^{a}$ Calculated using a population-based denominator.

${ }^{b}$ Age at time of event.

'Designed to primarily compare HEU and HU infants for an infection-related morbidity.

DRC, Democratic Republic of Congo; HEU, HIV exposed uninfected; HR, hazard ratio; HU, HIV unexposed; IPD, invasive pneumococcal disease; IRR, incidence rate ratio; OR, odds ratio; PR, prevalence ratio; $R C T$, randomized controlled trial; $R R$, risk ratio; VTP, vertical transmission prevention; prefix "a," adjusted; prefix " $u$," unadjusted. 
(17, 27-29, 33-51). Among the 21 African studies, 14 were conducted prior to 2009 in the context of limited ARV interventions for either maternal health or VTP. Only three studies were designed to primarily compare these two groups of infants (Table 2 studies 11, 17, and 21) (41, 46, 50). A major limitation of these studies is either due to study design or measurement limitations, they have not consistently considered confounding by universal infant risk factors of infectious morbidity and mortality; therefore, the role of direct HIV-exposure on infectious disease susceptibility is unclear.

\section{All-Cause Mortality and Hospitalization}

Studies conducted early in the epidemic did not observe significant differences in mortality, hospitalization, or infectious morbidities between HEU and HU children $(28,29)$. The first study to definitively demonstrate a higher mortality and morbidity in HEU compared to HU infants was the Zimbabwe Vitamin A for Mothers and Babies Project (ZVITAMBO) (Table 2 study 4), detailed further in this issue $(33,34)$. This large cohort study was conducted prior to the availability of either ARVs for treatment or prevention of HIV transmission or cotrimoxazole chemoprophylaxis, and $94 \%$ of infants breastfed until 12 months of age. The study demonstrated an almost four times greater risk of mortality [incidence rate ratio (IRR) 3.9, 95\% CI 3.2-4.8] at 12 months and two times greater risk of mortality (IRR 2.0, 95\% CI 1.2-3.5) at 24 months in HEU compared to HU infants (33). Similar to HU infants, the highest absolute mortality for HEU infants was in the neonatal period. The relative increase in HEU mortality was greatest between 2 and 6 months of life, reaching 5.5 (95\% CI 3.9-7.9) times that of HU infants (33). Eighty percent of HEU mortality occurred during the first 6 months of life. Morbidity, measured as sick clinic visits and hospitalizations, was also greater in HEU than in HU infants (34). Smaller Southern and Eastern African studies confirmed the elevated morbidity and mortality in HEU infants in this region $(17,35)$. The Mashi study in Botswana (Table 2 study 5) similar to ZVITAMBO observed an at least four times greater risk for mortality and double the risk for hospitalization at 6 and 24 months (35).

Two Ugandan studies designed primarily to evaluate prolonged co-trimoxazole preventive therapy for malaria chemoprophylaxis, or improvement of HEU health did not find substantial differences in infectious morbidity (Table 2 studies 6 and 10) (36, 40). A single study outside of sub-Saharan Africa, utilizing the Danish national registry compared 260 Danish HEU children to 1300 matched HU children for risk of hospital admission before age 4 years (51). The IRR for all hospitalizations was 3.2 (95\% CI 2.8-3.7), but the difference between HEU and HU infants was in non-malignant hematological disease and other non-specific symptoms (IRR 3.2, 95\% CI 1.5-7.0) rather than infectious disease hospitalizations (IRR 1.0, 95\% CI 0.79-1.37). Three smaller Southern African studies, one from Mozambique and two from South Africa, showed an increased risk for hospitalization in HEU infants compared to HU infants while out-patient sick clinic visits remained similar in both groups (Table 2 studies 8 , 9 , and 11) $(38,39,41)$. Vaccination uptake was similar in both HEU and HU infants in the South African studies $(39,41)$. One of the South African studies specifically considered the severity of hospitalization events and observed a four times greater probability of hospitalization for very severe infectious events in HEU compared to HU infants with comparable durations of breastfeeding (41). Inconsistencies in infectious morbidity outcomes between the Ugandan, Danish, and Southern African studies may reflect regional differences in infectious morbidity risk in HEU infants, differences in the age profile of children observed, with younger infants observed in South Africa and Mozambique, or alternatively, differences in measurement and analysis of infectious morbidity outcomes.

Cohorts in Europe and the Americas have reported rates of hospitalization and other morbidities in HEU children without comparison to HU control groups. The European Collaborative Study followed more than 1600 HEU infants from 1985 to 2002. A hospitalization rate of 264/1000 child-years was observed, and the probability of hospitalization was not associated with sociodemographic factors (52). In a cohort of infants born between 1985 and 2006 in Belgium, the incidence rate of severe infections was 16.8/100 HEU infant years (53). In Puerto Rico and the United States between 1989 and 2001, 24\% (229/955) of HEU children were hospitalized in the first 2 years of life with respiratory tract infections occurring most frequently (16\%) followed by gastroenteritis (11\%) (54). A prospective study in Latin America and the Caribbean of HIV-infected mothers and their infants described infectious disease morbidity in 462 HEU infants up to six months of age between 2002 and 2004 (55). Hospitalizations occurred at least once in $17.5 \%$ of infants, the majority (53\%) of admissions due to lower respiratory tract infections (LRTI). Although these studies have provided valuable descriptions of HEU infants, it is difficult to interpret these findings in the absence of comparison to HU infants.

Despite some inconsistencies, the existing evidence suggests that HEU infants experience greater mortality and hospitalization than HU infants. The risk ratios (RRs) for hospitalization from the most recent South African and Mozambican studies are approximately 1.5 times higher in HEU compared to $\mathrm{HU}$ infants and although imprecise, raise the possibility of a strong association between HIV exposure and infectious morbidity (38, 41). HIV exposure without HIV infection could account for up to one-third of infectious cause hospitalizations in HEU infants. In South Africa, for example, with an HIV exposure prevalence of almost $30 \%$ this would translate to $12.5 \%$ of infectious cause hospitalizations in all HIV-uninfected infants under 6 months of age occurring as a consequence of being born to an HIV-infected mother. Therefore, in a birth cohort of approximately one million in South Africa, an excess 35000 infant hospitalizations would occur annually $(41,56,57)$. Even a RR of 1.1 would produce an annual excess of 8100 infant hospitalizations in the same South African birth cohort, still a considerable number.

\section{Diarrheal Disease}

One of the earliest observations of increased infectious morbidity in HEU infants was from a prospective cohort study in the Democratic Republic of Congo between 1989 and 1992 (Table 2 study 12) (27). HEU infants had almost double the incidence of persistent diarrhea than HU infants (4.9 vs. 2.7/100 person years) and the hazard of persistent diarrhea was increased further 
in HEU infants of mothers who died [hazard ratio (HR) 10.4, $p<0.005]$. In a Kenyan study (Table 2 study 14), the prevalence of Cryptosporidium species was three times higher in HEU than HU children with acute diarrhea (43). The risk of diarrheal disease is intricately tied to infant feeding practices, presenting challenges in understanding whether diarrhea-related morbidity is due entirely to suboptimal breastfeeding in HEU infants or whether HIV exposure specific risk factors also play a role. In a South African non-randomized intervention cohort designed to determine the effect of exclusive breastfeeding on HIV transmission and to determine effectiveness of peer support on rates of exclusive breastfeeding (Table 2 study 13), all infants exclusively breastfed in the first 6 months of life presented with fewer diarrheal days than mixed or no breastfeeding with no difference between HEU and HU infants (42).

\section{Respiratory Infections}

A number of studies have described the burden of respiratory tract infections in HEU infants, but without HU control groups, it has not been possible to understand whether these HEU infants are experiencing the morbidity expected of all infants in their context or something in excess of that $(16,54,58,59)$. In two studies with appropriate $\mathrm{HU}$ comparison groups, although the most common reason for admission of HEU infants was for a LRTI, this rate was no different than that in $\mathrm{HU}$ infants requiring hospitalization for LRTIs (Table 2 studies 5 and 11) $(35,41)$. In a third study, HEU infants had a marginally significantly greater risk than $\mathrm{HU}$ infants for all pneumonia (hospitalized and out-patient cases) in the first year of life. However, they were at substantially higher risk for severe pneumonia (Table 2 study 18) (47). Additionally, it has been consistently observed in South African and Botswanan studies that HEU infants fail empiric pneumonia treatment more often than HU infants (Table 2 studies 15-17) (44-46). Although HEU infants experience a substantial burden of respiratory tract infections as reflected by the incidence of disease, this incidence is no different to HU infants in the same settings $(35,47)$. These two groups of infants may differ in the severity of the LRTIs and this is an observation that deserves further evaluation.

\section{Bacterial Sepsis}

Irrespective of HIV exposure, the risk for bacterial sepsis is highest during the neonatal period when the immature neonatal immune system is often unable to contain bacterial infections (60, 61). Considering all-cause neonatal sepsis in a large South African neonatal cohort, HEU neonates had a slightly lower rate than $\mathrm{HU}$ neonates for early onset ( $0-7$ days of life) and similar rate for late onset (8-28 days of life) neonatal sepsis (Table 2 study 19) (48). This persisted in a second analysis using propensity score matching to deal with differences in potentially confounding variables between HIV-infected and HIV-uninfected mothers. Group B Streptococcus (GBS) infection though is significantly increased in Belgian and South African HIV-exposed neonates (62-64). A Belgian retrospective cohort study observed an almost 20 times (RR 19.7, 95\% CI 7.5-51.7) greater risk of confirmed GBS infection in HEU infants compared to the population rate for $\mathrm{HU}$ infants between 2001 and 2008 (62). This increased risk was also associated with more severe manifestations of disease including septic shock, meningitis, and late-onset disease. In South Africa, HIV-exposed infants had a 70\% greater risk of early onset GBS disease (IRR 1.69, 95\% CI 1.28-2.24) and three times increased risk of late-onset GBS disease (IRR 3.18, 95\% CI 2.34-4.36), with replication of these findings in a later study in the same population $(63,65)$.

A South African nationwide invasive pneumococcal disease (IPD) laboratory surveillance study showed that during the first 6 months of life HEU South African infants have a three times greater risk for IPD that includes pneumonia, bacterial septicemia, and meningitis when compared to HU infants, and almost double the probability of IPD mortality independent of infant pneumococcal vaccination (Table 2 study 21) (50). In keeping with this, a four times greater risk for IPD was observed in Belgian HEU infants, born between 1985 and 2006, compared to the general infant population prior to pneumococcal conjugate vaccination (53). The risk for all-cause bacterial sepsis has not been evaluated in HEU infants directly compared to HU infants beyond the neonatal period. The French Perinatal Cohort showed an association in HEU infants between serious bacterial infections and maternal CD4 count near delivery (66). In this study of 7638 infants, the adjusted HRs for a serious bacterial infection were 1.7 (95\% CI 1.2-2.6) and 1.2 (95\% CI 0.8-1.9) for infants of mothers with CD 4 count below 350 cells $/ \mu$ l and 350-500 cells/ $\mu 1$ respectively, compared to above 500 cells/ $\mu$ l. This suggests that severe maternal immune compromise may increase the risk for serious bacterial infections in HEU infants.

\section{Viral Infections}

Vertical infection of HEU infants with other viral infections is important to consider, most notably due to cytomegalovirus (CMV), but also due to Human Herpes Virus 6 (HHV-6) (67, 68). Direct comparisons of rates of congenital CMV in HEU and $\mathrm{HU}$ infants have not been published. There is indirect evidence to suggest that HEU infants may experience greater risk of congenital viral infections. HIV-infected mothers more often transmit CMV and HHV-6 to their infants than HIV-uninfected mothers (68). In both the United States and South Africa, a congenital CMV prevalence of approximately $3 \%$ has been documented and is associated with features of advanced maternal HIV disease, high HIV viral load, and CD4 count of below 200 cells/ $\mu$ l (69, 70). The French Perinatal Cohort has observed a reduction in the prevalence of congenital CMV over time as combination ARV therapy has expanded, decreasing from 3.5\% in 1997-1998 to $1.2 \%$ in 2003-2004 (67).

\section{Infectious Morbidity Pattern}

From the studies reviewed, three patterns become evident:

(1) The causes of morbidity and mortality in HEU infants in sub-Saharan Africa are no different to the common causes of childhood morbidity and mortality in HU infants pneumonia, diarrheal disease, and bacterial sepsis predominate. These common childhood infections may occur with greater severity in HEU infants resulting in a higher mortality, more frequent hospitalization, and more severe manifestations of disease $(33-35,38,41,45-47,50)$; 
(2) HEU infants are at greater risk than HU infants for invasive streptococcal infections specifically GBS and Streptococcus pneumoniae (50, 62, 63);

(3) The neonatal period presents an increased risk for infectious morbidity in all infants, irrespective of HIV exposure. The greatest relative difference between HEU and HU infants occurs beyond the neonatal period, during mid-infancy. This is evidenced by the absence of a difference in all-cause neonatal sepsis and the relative increase in mortality in HEU compared to $\mathrm{HU}$ infants peaking between 2 and 6 months of age $(33,48)$.

\section{FUTURE RESEARCH CONSIDERATIONS}

To definitively understand HEU infant infectious morbidity risk, substantially larger prospective studies with appropriate HU infant comparison groups are needed. HEU infants would benefit from enhanced collaboration among researchers to achieve the quality of evidence required to improve HEU infant outcomes globally. Agreement on standardized infectious morbidity outcome measurement would allow for collaboration of multiple cohorts while still pursuing unique individual hypotheses and objectives. It is fully recognized that enhanced efforts to improve uptake of sustained breastfeeding in HIV-exposed infants are required. However, there is evidence that supports that pathways other than deprivation of breast milk require consideration and study to comprehensively understand HEU infant risk for infectious morbidity $(33,34,41,71)$. In designing further studies and looking for possible interventions to secure HEU infant well-being, researchers need to be cognizant of the vulnerabilities that all infants and children experience, whether HIV exposed or not. Interventions that are found to improve health in HEU infants may very well also improve outcomes for HU infants. The

\section{REFERENCES}

1. Joint United Nations Programme on HIV/AIDS (UNAIDS). Global Report: UNAIDS Report on the Global AIDS Epidemic 2013. Geneva: WHO (2013).

2. Chen JY, Ribaudo HJ, Souda S, Parekh N, Ogwu A, Lockman S, et al. Highly active antiretroviral therapy and adverse birth outcomes among HIV-infected women in Botswana. J Infect Dis (2012) 206(11):1695-705. doi:10.1093/ infdis/jis553

3. Sofeu CL, Warszawski J, Ateba Ndongo F, Penda IC, Tetang Ndiang S, Guemkam G, et al. Low birth weight in perinatally HIV-exposed uninfected infants: observations in urban settings in Cameroon. PLoS One (2014) 9(4):e93554. doi:10.1371/journal.pone.0093554

4. Humphrey JH. The risks of not breastfeeding. J Acquir Immune Defic Syndr (2010) 53(1):1-4. doi:10.1097/QAI.0b013e3181bf91da

5. Black RE, Cousens S, Johnson HL, Lawn JE, Rudan I, Bassani DG, et al. Global, regional, and national causes of child mortality in 2008: a systematic analysis. Lancet (2010) 375(9730):1969-87. doi:10.1016/ S0140-6736(10)60549-1

6. WHO Collaborative Study Team. Effect of breastfeeding on infant and child mortality due to infectious diseases in less developed countries: a pooled analysis. WHO Collaborative Study Team on the Role of Breastfeeding on the Prevention of Infant Mortality. Lancet (2000) 355(9202):451-5. doi:10.1016/ S0140-6736(00)82011-5

7. Newell M-L, Coovadia H, Cortina-Borja M, Rollins N, Gaillard P, Dabis F, et al. Mortality of infected and uninfected infants born to HIV-infected bigger picture of improving health and well-being for all infants particularly in Africa needs to be kept in mind. HEU infants comprise almost one-third of the infant population in high burden countries and their health and well-being, beyond avoiding HIV-infection, deserve a more prominent position in the local and international HIV research agendas.

\section{AUTHOR CONTRIBUTIONS}

AS conceived of the review, conducted the systematic review, and wrote the first draft of the manuscript. MC, JS, and JB supervised the work of AS and provided editorial input into the manuscript. TG provided editorial input into the manuscript.

\section{ACKNOWLEDGMENTS}

We are indebted to Professors Monika Essser, David Speert and Tobi Kollmann for their pioneering insight in recognizing HEU infants as a high risk group for infectious morbidity and their continued encouragement in pursuit of solutions to improving HEU infant and child outcomes.

\section{FUNDING}

This work was supported by a Major Thematic Grant from the Peter Wall Institute for Advanced Studies, University of British Columbia [grant number F0906208] and the Canadian Institutes of Health Research Canada-Hope programme [grant number CH1-106949]. Dr. Slogrove was supported by research fellowships from the Canadian Institutes of Health Research Canada-Hope Programme, The Canadian HIV Trials Network International Fellowship and the South African National Health Scholarship Programme. Dr. Bettinger is a Michael Smith Foundation for Health Research Scholar.

mothers in Africa: a pooled analysis. Lancet (2004) 364(9441):1236-43. doi:10.1016/S0140-6736(04)17140-7

8. Kuhn L, Aldrovandi GM, Sinkala M, Kankasa C, Semrau K, Mwiya M, et al. Effects of early, abrupt weaning on HIV-free survival of children in Zambia. $N$ Engl J Med (2008) 359(2):130-41. doi:10.1056/NEJMoa073788

9. Cotton MF, Schaaf HS, Lottering G, Weber HL, Coetzee J, Nachman S, et al. Tuberculosis exposure in HIV-exposed infants in a high-prevalence setting. Int J Tuberc Lung Dis (2008) 12(2):225-7.

10. Joint Learning Initiative on Children and HIV/AIDS. Home Truths. Facing the Facts on Children, AIDS and Poverty. UNICEF (2009). Available at: http://www.unaids.org/en/resources/presscentre/featurestories/2009/ january/20090219jlica

11. Sherr L, Cluver LD, Betancourt TS, Kellerman SE, Richter LM, Desmond C. Evidence of impact: health, psychological and social effects of adult HIV on children. AIDS (2014) 28(Suppl 3):S251-9. doi:10.1097/QAD.0000000000000327

12. Bunders MJ, Van Hamme JL, Jansen MH, Boer K, Kootstra NA, Kuijpers TW. Fetal exposure to HIV-1 alters chemokine receptor expression by CD $4+$ T cells and increases susceptibility to HIV-1. Sci Rep (2014) 4:6690. doi:10.1038/ srep06690

13. De Maria A, Cirillo C, Moretta L. Occurrence of human immunodeficiency virus type 1 (HlV-l) - specific cytolytic T cell activity in apparently uninfected children born to HIV-1-infected mothers. J Infect Dis (1994) 170(5):1296-9. doi:10.1093/infdis/170.5.1296

14. Rowland-Jones SL, Nixon DF, Aldhous MC, Gotch F, Ariyoshi $\mathrm{K}$, Hallam $\mathrm{N}$, et al. HIV-specific cytotoxic T-cell activity in an 
HIV-exposed but uninfected infant. Lancet (1993) 341:860-1. doi:10.1016/0140-6736(93)93063-7

15. Clerici M, Saresella M, Colombo F, Fossati S, Sala N, Bricalli D, et al. T-lymphocyte maturation abnormalities in uninfected newborns and children with vertical exposure to HIV. Blood (2000) 96(12):3866-71.

16. Kuhn L, Kasonde P, Sinkala M, Kankasa C, Semrau K, Scott N, et al. Does severity of HIV disease in HIV-infected mothers affect mortality and morbidity among their uninfected infants? Clin Infect Dis (2005) 41(11):1654-61. doi:10.1086/498029

17. Brahmbhatt H, Kigozi G, Wabwire-Mangen F, Serwadda D, Lutalo T, Nalugoda F, et al. Mortality in HIV-infected and uninfected children of HIV-infected and uninfected mothers in rural Uganda. J Acquir Immune Defic Syndr (2006) 41(4):504-8. doi:10.1097/01.qai.0000188122.15493.0a

18. Mofenson LM, Watts DH. Safety of pediatric HIV elimination: the growing population of HIV- and antiretroviral-exposed but uninfected infants. PLoS Med (2014) 11(4):e1001636. doi:10.1371/journal.pmed.1001636

19. Afran L, Knight MG, Nduati E, Urban BC, Heyderman RS, Rowland-Jones SL. HIV-exposed uninfected children: a growing population with a vulnerable immune system? Clin Exp Immunol (2013) 176:11-22. doi:10.1111/cei.12251

20. Reikie BA, Adams RCM, Leligdowicz A, Ho K, Naidoo S, Ruck CE, et al. Altered innate immune development in HIV-exposed uninfected infants. J Acquir Immune Defic Syndr (2014) 66(3):245-55. doi:10.1097/ QAI.0000000000000161

21. Kuhn L, Meddows-Taylor S, Gray G, Tiemessen C. Human immunodeficiency virus (HIV)-specific cellular immune responses in newborns exposed to HIV in utero. Clin Infect Dis (2002) 34(2):267-76. doi:10.1086/338153

22. Bunders M, Thorne C, Newell ML, European Collaborative Study. Maternal and infant factors and lymphocyte, CD4 and CD8 cell counts in uninfected children of HIV-1-infected mothers. AIDS (2005) 19(10):1071-9. doi:10.1097/01.aids.0000174454.63250.22

23. Vigano A, Saresella M, Schenal M, Erba P, Pacentini L, Tornaghi R, et al. Immune activation and normal levels of endogenous antivirals are seen in healthy adolescents born of HIV-infected mothers. AIDS (2007) 21(2):245-8. doi:10.1097/QAD.0b013e328011d7d3

24. de Moraes-Pinto MI, Almeida ACM, Kenj G, Filgueiras TE, Tobias W, Santos AMN, et al. Placental transfer and maternally acquired neonatal IgG immunity in human immunodeficiency virus infection. J Infect Dis (1996) 173(5):1077-84. doi:10.1093/infdis/173.5.1077

25. de Moraes-Pinto MI, Verhoeff F, Chimsuku L, Milligan PJM, Wesumperuma L, Broadhead RL, et al. Placental antibody transfer: influence of maternal HIV infection and placental malaria. Arch Dis Child Fetal Neonatal Ed (1998) 79:F202-5. doi:10.1136/fn.79.3.F202

26. Jones CE, Naidoo S, De Beer C, Esser M, Kampmann B, Hesseling AC. Maternal HIV infection and antibody responses against vaccinepreventable diseases in uninfected infants. JAm Med Assoc (2011) 305(6):576-84. doi:10.1001/jama.2011.100

27. Thea DM, St. Louis ME, Atido U, Kanjinga K, Kembo B, Matondo M, et al. A prospective study of diarrhea and HIV-1 infection among 429 Zairian infants. N Engl J Med (1993) 329(23):1696-702. doi:10.1056/ NEJM199312023292304

28. Spira R, Lepage P, Msellati P, Van de Perre P, Leroy V, Simonon A, et al. Natural history of human immunodeficiency virus type 1 infection in children: a five-year prospective study in Rwanda. Pediatrics (1999) 104(e56):1-9. doi:10.1542/peds.104.5.e56

29. Taha TE, Graham SM, Kumwenda NI, Broadhead RL, Hoover DR, Markakis $\mathrm{D}$, et al. Morbidity among human immunodeficiency virus-1-infected and -uninfected African children. Pediatrics (2000) 106(6):e77. doi:10.1542/ peds.106.6.e77

30. Chatterjee A, Bosch RJ, Hunter DJ, Fataki MR, Msamanga GI, Fawzi WW. Maternal disease stage and child undernutrition in relation to mortality among children born to HIV-infected women in Tanzania. J Acquir Immune Defic Syndr (2007) 46(5):599-606. doi:10.1097/QAI.0b013e31815a5703

31. Kourtis AP, Wiener J, Kayira D, Chasela C, Ellington SR, Hyde L, et al. Health outcomes of HIV-exposed uninfected African infants. AIDS (2013) 27(5):749-59. doi:10.1097/QAD.0b013e32835ca29f

32. The Kesho Bora Study Group. Eighteen-month follow-up of HIV-1-infected mothers and their children enrolled in the Kesho Bora study observational cohorts. J Acquir Immune Defic Syndr (2010) 54(5):533-41. doi:10.1097/ QAI.0b013e3181e36634
33. Marinda E, Humphrey JH, Iliff PJ, Mutasa K, Nathoo KJ, Piwoz EG, et al. Child mortality according to maternal and infant HIV status in Zimbabwe. Pediatr Infect Dis J (2007) 26(6):519-26. doi:10.1097/01.inf.0000264527.69954.4c

34. Koyanagi A, Humphrey JH, Ntozini R, Nathoo K, Moulton LH, Iliff P, et al. Morbidity among human immunodeficiency virus-exposed but uninfected, human immunodeficiency virus-infected, and human immunodeficiency virus-unexposed infants in Zimbabwe before availability of highly active antiretroviral therapy. Pediatr Infect Dis J (2011) 30(1):45-51. doi:10.1097/ INF.0b013e3181ecbf7e

35. Shapiro RL, Lockman S, Kim S, Smeaton L, Rahkola JT, Thior I, et al. Infant morbidity, mortality, and breast milk immunologic profiles among breast-feeding HIV-infected and HIV-uninfected women in Botswana. J Infect Dis (2007) 196(4):562-9. doi:10.1086/519847

36. Homsy J, Dorsey G, Arinaitwe E, Wanzira H, Kakuru A, Bigira V, et al. Protective efficacy of prolonged co-trimoxazole prophylaxis in HIV-exposed children up to age 4 years for the prevention of malaria in Uganda: a randomised controlled open-label trial. Lancet Glob Health (2014) 2(12):e727-36. Homsy Open Access article distributed under the terms of CC BY. doi:10.1016/ S2214-109X(14)70329-8

37. Landes M, van Lettow M, Chan AK, Mayuni I, Schouten EJ, Bedell RA. Mortality and health outcomes of HIV-exposed and unexposed children in a PMTCT cohort in Malawi. PLoS One (2012) 7(10):e47337. doi:10.1371/ journal.pone.0047337

38. Moraleda C, de Deus N, Serna-Bolea C, Renom M, Quintó L, Macete E, et al. Impact of HIV exposure on health outcomes in HIV-negative infants born to HIV-positive mothers in Sub-Saharan Africa. J Acquir Immune Defic Syndr (2014) 65(2):182-9. doi:10.1097/QAI.0000000000000019

39. Slogrove A, Reikie B, Naidoo S, De Beer C, Ho K, Cotton M, et al. HIV-exposed uninfected infants are at increased risk for severe infections in the first year of life. J Trop Pediatr (2012) 58(6):505-8. doi:10.1093/tropej/fms019

40. Marquez C, Okiring J, Chamie G, Ruel TD, Achan J, Kakuru A, et al. Increased morbidity in early childhood among HIV-exposed uninfected children in Uganda is associated with breastfeeding duration. J Trop Pediatr (2014) 60(6):434-41. doi:10.1093/tropej/fmu045

41. Slogrove AL. The Pattern and Pathways of Infectious Morbidity in South African HIV Exposed Uninfected Infants. Vancouver: University of British Columbia (2015).

42. Rollins NC, Ndirangu J, Bland RM, Coutsoudis A, Coovadia HM, Newell M-L. Exlcusive breastfeeding, diarrhoeal morbidity and all-cause mortality in infants of HIV-infected and HIV uninfected mothers: an intervention cohort study in KwaZulu Natal, South Africa. PLoS One (2013) 8(12):e81307. doi:10.1371/journal.pone.0081307

43. Pavlinac PB, John-Stewart GC, Naulikha JM, Onchiri FM, Denno DM, Odundo EA, et al. High-risk enteric pathogens associated with HIV infection and HIV exposure in Kenyan children with acute diarrhoea. AIDS (2014) 28(July):2287-96. doi:10.1097/QAD.0000000000000396

44. Izadnegahdar R, Fox MP, Jeena P, Qazi SA, Thea DM. Revisiting pneumonia and exposure status in infants born to HIV-infected mothers. Pediatr Infect Dis $J$ (2014) 33(1):70-2. doi:10.1097/INF.0b013e31829f0ade

45. McNally LM, Jeena PM, Gajee K, Thula SA, Sturm AW, Cassol S, et al. Effect of age, polymicrobial disease, and maternal HIV status on treatment response and cause of severe pneumonia in South African children: a prospective descriptive study. Lancet (2007) 369(9571):1440-51. doi:10.1016/ S0140-6736(07)60670-9

46. Kelly MS, Wirth KE, Steenhoff AP, Cunningham CK, Arscott-Mills T, Boiditswe SC, et al. Treatment failures and excess mortality among hivexposed, uninfected children with pneumonia. J Pediatr Infect Dis Soc (2014) 4(4):e117-26. doi:10.1093/jpids/piu092

47. le Roux DM, Myer L, Nicol MP, Zar HJ. Incidence and severity of childhood pneumonia in the first year of life in a South African birth cohort: the Drakenstein Child Health Study. Lancet Glob Health (2015) 3(2):e95-103. doi:10.1016/S2214-109X(14)70360-2

48. Cutland CL, Schrag SJ, Zell ER, Kuwanda L, Buchmann E, Velaphi SC, et al. Maternal HIV infection and vertical transmission of pathogenic bacteria. Pediatrics (2012) 130(3):e581-90. doi:10.1542/peds.2011-1548

49. Madhi SA, Govender N, Dayal K, Devadiga R, Van Dyke MK, van Niekerk N, et al. Bacterial and respiratory viral interactions in the etiology of acute otitis media in HIV-infected and HIV-uninfected South African children. Pediatr Infect Dis J (2015) 34(7):753-60. doi:10.1097/INF.0000000000000733 
50. von Mollendorf C, von Gottberg A, Tempia S, Meiring S, de Gouveia L, Quan V, et al. Increased risk for and mortality from invasive pneumococcal disease in HIV-exposed but uninfected infants aged $<1$ year in South Africa, 2009-2013. Clin Infect Dis (2015) 60(9):1346-56. doi:10.1093/cid/ civ059

51. Larsen E, Lunding S, Helleberg M, Katzenstein T, Nordly S, Weis N, et al. Hospitalizations among uninfected children exposed or unexposed to HIV - a nationwide cohort. Abstract 877. Conference on Retroviruses and Opportunistic Infections. Seattle, Washington (2015). Available at: http:// www.croiconference.org/sessions/hospitalizations-among-uninfected-children-exposed-or-unexposed-hiv---nationwide-cohort

52. Hankin C, Thorne C, Peckham C, Newell M-L. The health and social environment of uninfected infants born to HIV-infected women. AIDS Care (2004) 16(3):293-303. doi:10.1080/09540120410001665303

53. Adler C, Haelterman E, Barlow P, Marchant A, Levy J, Goetghebuer T. Severe infections in HIV-exposed uninfected infants born in a European country. PLoS One (2015) 10(8):e0135375. doi:10.1371/journal.pone.0135375

54. Paul ME, Chantry CJ, Read JS, Frederick MM, Lu M, Pitt J, et al. Morbidity and mortality during the first two years of life among uninfected children born to human immunodeficiency virus type 1-infected women. Pediatr Infect Dis J (2005) 24(1):46-56. doi:10.1097/01.inf.0000148879.83854.7e

55. Mussi-Pinhata MM, Freimanis L, Yamamoto AY, Korelitz J, Pinto JA, Cruz MLS, et al. Infectious disease morbidity among young HIV-1-exposed but uninfected infants in Latin American and Caribbean countries: the National Institute of Child Health and Human Development International Site Development Initiative Perinatal Study. Pediatrics (2007) 119(3):e694-704. doi:10.1542/peds.2006-1856

56. Goga AE, Dinh TH, Jackson DJ. Evaluation of the Effectiveness of the National Prevention of Mother-To-Child Transmission (PMTCT) Programme on Infant HIV Measured at Six Weeks Postpartum in South Africa, 2010. South African Medical Research Council, National Department of Health of South Africa and PEPFAR/US Centers for Disease Control and Prevention. (2012) [cited 2015 Oct 17]. Available from: http://sanac.org.za/resources/ cat_view/7-publications/9-reports

57. Statistics South Africa. Recorded Live Births 2011 [Internet]. Pretoria; (2012) [cited 2015 Oct 17]. Available from: http://www.statssa.gov.za/publications/ P0305/P03052011.pdf

58. Mussi-Pinhata MM, Motta F, Freimanis-Hance L, de Souza R, Szyld E, Succi $\mathrm{RCM}$, et al. Lower respiratory tract infections among human immunodeficiency virus-exposed, uninfected infants. Int J Infect Dis (2010) 14(Suppl 3):e176-82. doi:10.1016/j.ijid.2010.01.006

59. Mwiru R, Spiegelman D, Hertzmark E, Duggan C, Msamanga G, Aboud S, et al. Nutritional predictors of acute respiratory infections among children born to HIV-infected women in Tanzania. J Trop Pediatr (2013) 59(3):203-8. doi:10.1093/tropej/fmt004

60. Santos RP, Tristram D. A practical guide to the diagnosis, treatment, and prevention of neonatal infections. Pediatr Clin North Am (2015) 62(2):491-508. doi:10.1016/j.pcl.2014.11.010

61. Schelonka RL, Infante AJ. Neonatal immunology. Semin Perinatol (1998) 22(1):2-14. doi:10.1016/S0146-0005(98)80003-7

62. Epalza C, Goetghebuer T, Hainaut M, Prayez F, Barlow P, Dediste A, et al. High incidence of invasive group $\mathrm{B}$ streptococcal infections in
HIV-exposed uninfected infants. Pediatrics (2010) 126(3):e631-8. doi:10.1542/ peds.2010-0183

63. Cutland CL, Schrag SJ, Thigpen MC, Velaphi SC, Wadula J, Adrian PV, et al. Increased risk for group B Streptococcus sepsis in young infants exposed to HIV, Soweto, South Africa. Emerg Infect Dis (2015) 21(4):638-45. doi:10.3201/ eid2104.141562

64. Dangor Z, Kwatra G, Izu A, Adrian P, van Niekerk N, Cutland CL, et al. HIV-1 is associated with lower group B Streptococcus capsular and surface-protein IgG antibody levels and reduced transplacental antibody transfer in pregnant women. J Infect Dis (2015) 212:453-62. doi:10.1093/infdis/jiv064

65. Dangor Z, Lala SG, Cutland CL, Koen A, Jose L, Nakwa F, et al. Burden of invasive group B Streptococcus disease and early neurological sequelae in South African infants. PLoS One (2015) 10(4):e0123014. doi:10.1371/journal. pone.0123014

66. Taron-Brocard C, Le Chenadec J, Faye A, Dollfus C, Goetghebuer T, Gajdos V, et al. Increased risk of serious bacterial infections due to maternal immunosuppression in HIV-exposed uninfected infants in a European country. Clin Infect Dis (2014) 59(9):1332-45. doi:10.1093/cid/ciu586

67. Guibert G, Warszawski J, Le Chenadec J, Blanche S, Benmebarek Y, Mandelbrot L, et al. Decreased risk of congenital cytomegalovirus infection in children born to HIV-1-infected mothers in the era of highly active antiretroviral therapy. Clin Infect Dis (2009) 48(11):1516-25. doi:10.1086/ 598934

68. D’Agaro P, Burgnich P, Comar M, Dal Molin G, Bernardon M, Busetti $\mathrm{M}$, et al. HHV-6 is frequently detected in dried cord blood spots from babies born to HIV-positive mothers. Curr HIV Res (2008) 6(5):441-6. doi:10.2174/157016208785861122

69. Duryea EL, Sánchez PJ, Sheffield JS, Jackson GL, Wendel GD, McElwee BS, et al. Maternal human immunodeficiency virus infection and congenital transmission of cytomegalovirus. Pediatr Infect Dis J (2010) 29(10):915. doi:10.1097/INF.0b013e3181e0ce05

70. Manicklal S, Van Niekerk AM, Kroon SM, Hutto C, Novak Z, Pati SK, et al. Birth prevalence of congenital cytomegalovirus among infants of HIV-infected women on prenatal antiretroviral prophylaxis in South Africa. Clin Infect Dis (2014) 58(10):1467-72. doi:10.1093/cid/ciu096

71. Fox MP, Brooks DR, Kuhn L, Aldrovandi G, Sinkala M, Kankasa C, et al. Role of breastfeeding cessation in mediating the relationship between maternal HIV disease stage and increased child mortality among HIV-exposed uninfected children. Int J Epidemiol (2009) 38(2):569-76. doi:10.1093/ije/ dyn 249

Conflict of Interest Statement: The authors declare that the research was conducted in the absence of any commercial or financial relationships that could be construed as a potential conflict of interest.

Copyright (c) 2016 Slogrove, Goetghebuer, Cotton, Singer and Bettinger. This is an open-access article distributed under the terms of the Creative Commons Attribution License (CC BY). The use, distribution or reproduction in other forums is permitted, provided the original author(s) or licensor are credited and that the original publication in this journal is cited, in accordance with accepted academic practice. No use, distribution or reproduction is permitted which does not comply with these terms. 